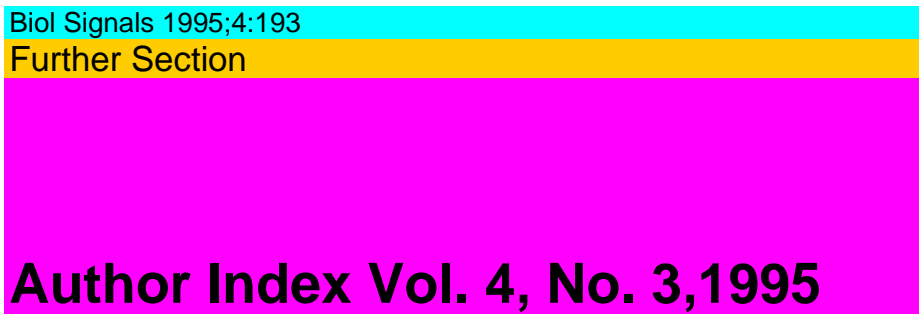

\title{
Author Index Vol. 4, №. 3,1995
}

\author{
Ballard, H.J. 168 \\ Chan,Y.S. 133 \\ Chen, H.I. 186 \\ Chiu,T.H. 117 \\ Coote,J.H. 142 \\ Dinger, B.G. 109 \\ Dun,N.J. 117 \\ Dun,S.L. 117 \\ Fidone,S.J. 109 \\ Han,C. 150 \\ Huang, R. 117 \\ Kao,K.-M. 124 \\ Kravtsov, G.M. 160 \\ Kwan,C.Y. 160 \\ Li, P. 124
}

Lin,Q. 124

Lu,Z. 150

Lung,M.A. 179

Qu,P. 150

Shen,E. 117

Sheng,J.Z. 174

Stensaas,L.J. 109

Sun,S.-Y. 124

Tai,K.K. 174

Tang,H. 117

Wang,Z.-Z. 109

Wong,N.S. 174

Wong,T.M. 133,174

$\mathrm{Xu}, \mathrm{K} .150$

Zhu,D.-N. 124 